\title{
The Analysis of Influence of River Floods on Biotic Components of Floodplain Ecosystems with the Help of MATLAB Simulation
}

\author{
Vladimir Petrovich Bolotnov \\ Yugra State University \\ Russia
}

\section{Introduction}

The Ob River occupies a central place in Western Siberia. Its basin comprises all spatial and dynamic variability typical for Western Siberian ecosystems. The river floodplains are the most dynamic parts and in the same time host most of the human activities. However, at present spatial planning of economic activities in the floodplain areas cannot be based on water regime and geomorphologic processes, because relevant inventory of relief and hydrological monitoring data are hardly accessible. Moreover, for nature conservation, in terms of planning, area selection and management, and data of biodiversity of floodplain ecosystems are missing.

This research intends to fill these gaps in knowledge. In addition factual relations between ecosystem productivity of different floodplain units and hydrological regime need to be studied. There to a hydro-ecological monitoring scheme for analyses of the Ob-Irtysh floodplain of the region Middle Ob will be set up.

The research will be based on the already developed hydro-ecological zone maps and hydrological data of hydro-meteorological stations (river stages dynamics) representative for different river floodplain sections.

The monitoring results of a period of more 50 years stage observations flood hydrographs have been plotted and frequencies and duration of floods and relations with geomorphologic characteristics of floodplain relief and flood depths been calculated. These data may need to be evaluated more thoroughly and thereafter compared with ecosystem productivity data, which will be gathered within the scope of this project. The bird population is considered as the most sensitive element of the ecosystem.

Birds are an important component of ecosystems. They function as the consumers of the first and second orders in the trophic chain of an ecosystem. The main factor determining the annual dynamics of the bird population in the West Siberia is migration. In autumn the majority of bird population leaves for south, in spring they come back, and the time of return coincides with the period of spring high water in the Ob. This period also coincides with the breeding stage. The floodplain of the $\mathrm{Ob}$ attracts birds in the first place. It is related to the warming action of the waters that the river brings from south to north and to the more productive and diverse habitat conditions than in the interfluve territory. The $\mathrm{Ob}$ valley serves as a kind of air channel, along which the majority of birds moves. The years 
when the water-content parameters are close to the mean annual values are especially favorable, while those with low or extremely high water-content parameters are unfavorable (Adam A. M. \& Bolotnov, 1982-2010). Thus, from the point of view of the monitoring of the state of the floodplain ecosystem the birds serve as a good indicator of its state in terms of hydro-thermal conditions. In addition to that, they occupy an important place in the nature management of the region, since a significant part of the waterbird population is a major hunting resource actively used by the local people and hunters from other regions.

\section{A Model of the population dynamics of birds in the river floodplain}

In the early 1980s, various large-scale projects of the change of the Ob flow as a result of hydroplant reservoirs construction (Katun and Krapivinski hydroplants) were developed as well as the projects to divert some of the waters to south, regional projects to change the irrigation of territory in terms of farming and fishing ameliorations, realization of which resulted in the local changes of the flooding conditions in the floodplain of the middle $\mathrm{Ob}$. At the same time a scheme of interaction of the birds and water regime of the $\mathrm{Ob}$ was formed (Adam A. M. \& Bolotnov, 1982-2001, Ravkin,2004, Vartapetov,2004). Accumulation of the empirical data allowed the experts to pass on to the building of a model of the bird population dynamics in the middle course of the Ob (Adam A. M. \& Bolotnov, 2000-2001). It was represented as the structural scheme of the model, mathematical description (system of equations and graphs of the relations between the components of ecosystem based on real data) and complemented with the results of the modeling of a real object, which allowed us to improve its structure.

\subsection{The physiographic and ecological description region research}

The simulation model is built for the central region of the Ob floodplain in Tomsk oblast with the area of $4142 \mathrm{~km} 2$ located within the administrative boundaries of Kolpashevo raion. Flowing through the territory of Tomsk region from the south-east to the north-west, the $\mathrm{Ob}$ River crosses the sub zone of the south and partially of the northern taiga. The length of the area is equal to $1169 \mathrm{~km}$, which is almost $1 / 3$ of the whole Ob River length $(3676 \mathrm{~km})$. The further rivet goes from the south to the north the higher watering it shows due to river inflows. The main phase of the water regime is snow-rain flood, which can be observed during spring-summer period from April till August. The is $70 \%$ of annual outflow drains during the period of spring high water. The Ob River valleys are characterized by vast floodplain, cut across with numerous channels, floodplain rivers, lakes. It's width changes from $6 \mathrm{~km}$ in the south (Kozhevnikovo hydrometric station) to $20 \mathrm{~km}$ in the north (Moltchanovo, Alexandrovskoye hydrometric stations) The course of the river is badly curved and crossed with little islands in many zones.

It causes the river banks' erosion which was assisted by small depths and low speeds of a flow. Inclination of the water surface is insignificant - 0,044 \%o. Average speed of a flow to a lowest water level is $0,5 \ldots 0,7 \mathrm{M} / \mathrm{c}$, and in a period of high water is $2,0 \ldots 2,5 \mathrm{M} / \mathrm{c}$. The average annual outflow varies from $60 \mathrm{~km} 3$ (Pobeda hydrometric station) to $195 \mathrm{~km} 3$ (Alexandrovskoye hydrometric station).

Floods wave through the river valley. As a result the maximal levels are reached nonsimultaneously in river ranges but move in time one relatively another. Combining in one draft the schedules of flood waving in different ranges (Fig.3) we can find an obvious conception of the river regime in this very period in different ranges and of meadow high and duration. 
Spring level increase normally starts in the second part of April (early and late periods are the beginning or the end of April), even while freezing over. In general water level flow of the $\mathrm{Ob}$ river we observe one wave with intensive increase and very slow reduce. In the area of Tom river inflow we can observe crested water flow or two-three weaked waves of flood, appeared as a result of split of multy-peaked flood in the upper reaches of the $\mathrm{Ob}$ river. Duration of the floodplain can last from 120 days while "friendly" springs till 150 days. An average duration of a low meadow flood can consists of 8-12 days by Kruglikovo hydrometric station, 63 days by Kolpashevo hydrometric station and 68 days by Alexandrovskoye hydrometric station. The longest period of middle $\mathrm{Ob}$ meadow flood lasts for 2-3,5 months. Although in the north from Alexandrovskoye water point given water horizons can be observed for 2-2,5 months later than around Kruglicovo hydrometric station in a period of long springs. The end of floodplain normally comes in July or August. An average height of water level increase above pre-flood period is equal to $5 \mathrm{vm}$ (before Tom river inflow), than 7-8 and than the highest 9-11 (Alexandrovskoye hydrometric station). Duration of level increase period is about 30-35 days with average insensitivity of increase as of $30-35 \mathrm{~cm}$ per 24 hours.

Analysis of yearly water point level shows that the whole meadow of the Ob river is filled with water when floodplain reaches the maximal level $10-1 \%$ of provision. That's why we rarely see the common flood, it happens once per 30-50 years or even more seldom. At the same time the low meadow of the $\mathrm{Ob}$ river from Kolpashevo hydrometric station to the northern boundary goes under water every year. So the low part of the meadow is more adopted for floodplain impact and low water floods or floods for short periods can be born badly. This situation is quiet rare as the Ob river (in the lower area of the Ket river inflow) exists in a natural regime and high side inflow, huge water cumulative basin, which forms water reserves while autumn-winter season. These reserves provide obligatory spring floodplain. When analyzing the flood the meadow area is usually divided into high, middle and low areas. This dividing is equal to levels which are higher than $25 \%$ of provision and average multy-year frequency of flooding once per 4 years, close to $50 \%$ of provision and flooding once per 2 years, and lower than $75 \%$ of provision, with every year flooding. Often this division happens not objectively - by vegetation which is a vivid indicator of flooding. However the usage of counting characteristics of provision lets apply fixed marks of the flood level and refer them to meadow relief and find not only the fact of flooding and also give quantity characteristics of its duration, height of filling and starting and finishing date. It is very important for the low meadow areas which are flooded every year but also have differences in parameters. Dividing of the low meadow territory within the boundaries of $100-95 \%$ of provision permits basically perform the part from the whole annually flooded territory.

For this purpose we used the long-term observations (1977-2000) conducted in spring and summer, when the influence of spring high waters and other ecological factors on the spatial-temporal structure of the bird population was studied in detail. The average bird population in the floodplain varies from 1000 (willow forests) to $47 \mathrm{ind} / \mathrm{km} 2$ (river). The highest population density is recorded in the villages on the river banks, which varies from 1500 in the first half of summer to 4000 ind $/ \mathrm{km} 2$ in the second half. The value of the parameters decreases as the complexity of habitats diminishes, the relief lowers, and the moisture level grows (from forests and shrubs to the meadows of high ridges, meadows of depressions, lakes and watercourses). In the second half of summer almost in all habitats the bird abundance increases 1.5 times. In the forest habitats the yellow-breasted bunting, coal 
tit, and long-tailed tit dominate in abundance, and in the shrub habitats, the reed bunting. The yellow-breasted and reed buntings dominate in meadows, too. In the over-wet and wet meadows and lakes the Pallas's grasshopper warbler and garganey are abundant. The sand martin dominates on the $\mathrm{Ob}$ and outlets. In the villages the Eurasian tree sparrow and barn swallow dominate. In total about 128 bird species live in the area, which can be divided into 6 ecological groups by their habitats: forest-shrub birds, 59 species; birds of dry meadows, 9 species (the common quail, skylark); birds of wet meadows, 12 species (the corn crake, great snipe, common snipe); water-bog birds on the over-wet and flooded meadows, 8 species (the Eurasian bittern, mallard); birds of the waterbodies, 21 species (the common teal, common pochard, tufted duck); birds associated with villages, 11 species (the barn swallow, Eurasian tree and house sparrows) (Vartapetov, 1984, Yudkin, 1987). The group of birds of wet meadows is the most dynamic by the value of the year-to-year changes.

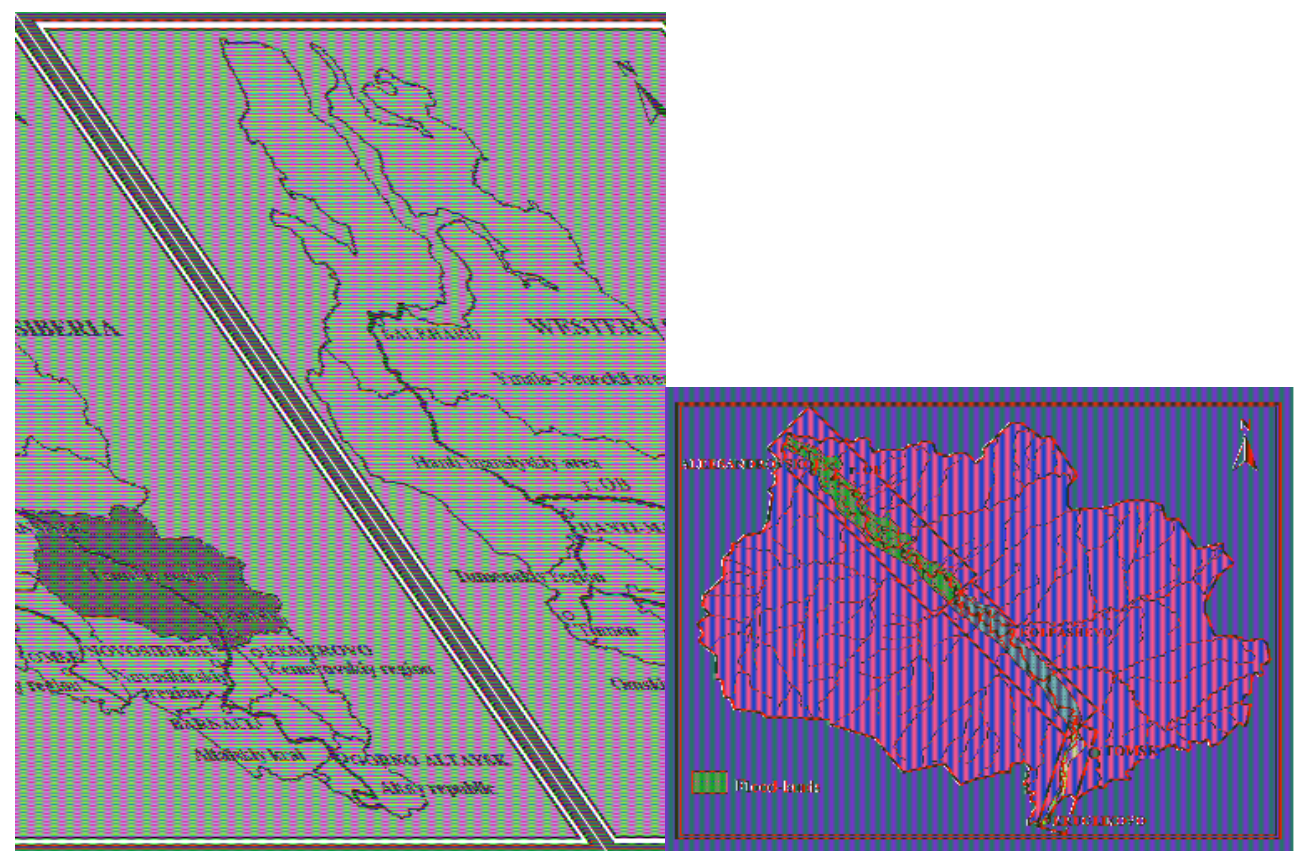

Fig. 1. Maps-schemes of regione research.

\subsection{Foundations of the modeling}

The model of dynamics of the bird population is built on the principles of system dynamics suggested by Jay Forrester (Forrester, 1978). It is based on the idea of phase coordinates of the system characterizing the system state in a given moment. If the external influence on the system is known, the knowledge of the phase coordinates in a moment of time helps to determine the system state in the following moments. After Forrester we use the term "stock" to mark this parameter and "flow" to characterize its changes. The basic cells building the system are the chains of feedback and feedforward. The flow is the reason of the stock changes. The data on the stocks are the inputs for the flow equations, which regulate the flows. The variables of the flows depend only on information on stocks. One 
stock influences another through the flows. Two main loops that influence the bird population density value are represented in Figure 1. The upper loop determines the flow of density increase (FDI), the lower, the flow of density decrease (FDD). NFDI and NFDD are normal flow of density increase and normal flow of density decrease corresponding to the mean annual conditions.

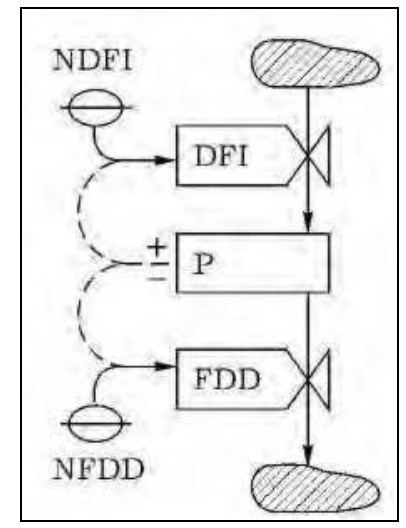

Fig. 2. Basic loops of feedback and feedforward in the model structure.

The model reflects the interaction of the biological component of the floodplain ecosystem (birds) with the external natural conditions, i.e., we consider the system "biocomponentenvironment" based on the principles of self-regulation. The environment includes the species territory, vegetation, climate factor, influence of high water. The high water is a leading factor for the given territory. AF (anthropogenic factor) is the abbreviation used in the model; it means the sum of anthropogenic impact and environmental changes (AF + EC). This is supposed to underline the leading position of this factor in the system dynamics, since the anthropogenic factor can change environment by $50 \%$ and more through change of the conditions of the floodplain flooding (farming and fishing amelioration), birds shooting in the spring hunting period, factor of trouble during haymaking, fishing, recreation, etc. The use of the system "component of ecosystemenvironment-anthropogenic factor" is typical of the models of this kind. In the given system the block AF has an expressed social function and is determined by the economical and social laws of the society. Analysis of the organization of this block at the given stage is not significant, since the model is of prognostic character with respect to the real changes of the water regime. The effect of the social factor was specified through limiting or changing the effect of the natural factors. The orientation of the model concept for the purpose of the region management would require creating a social block. Now the approaches to the forming of the social block (AF) are being formed based on the ecological- economical criteria of the nature management, which are given in (Adam, Mamin, 2000, Adam,et al., 2000).

\subsection{Structure of the model}

Figure 2 shows the concept of the simulation model reflecting the relation between the dynamics of the bird population density and abiotic, biotic, and anthropogenic factors of the natural-territorial complex of the floodplain of the middle Ob. It reflects the basic 


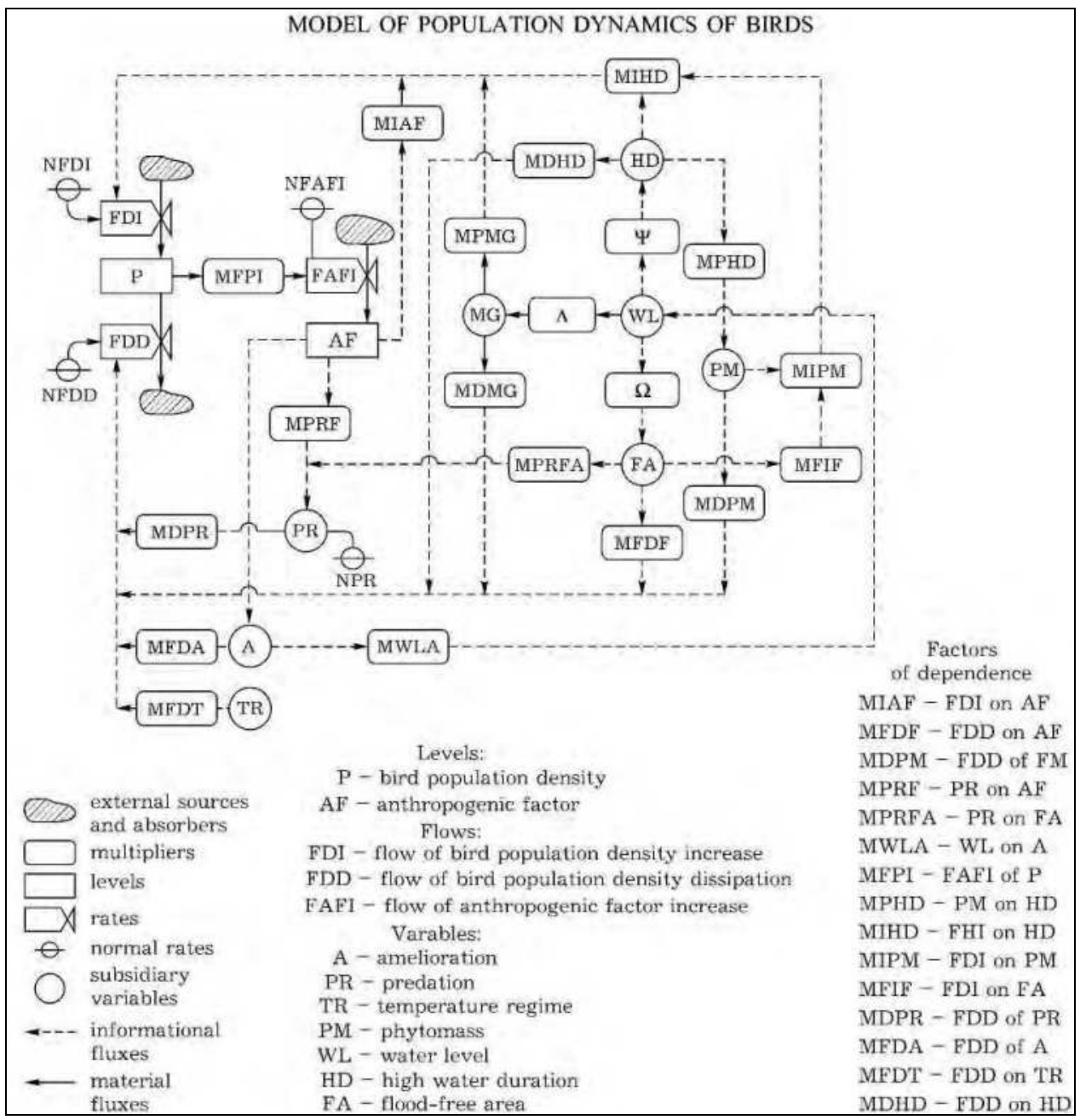

Fig. 3. Structure of the model of the dynamics of the bird population density in the floodplain of the middle $\mathrm{Ob}$.

interrelations between the variables (factors) included in the model. The following parameters are chosen as the stocks forming the system structure: bird population density (P) and anthropogenic factors (AF). The marks of irregular shape ("cloud-like") - inflows or outflows - are positioned outside the system. Any closed loop is a feedback loop. The stock introduced to the system (AF) reflects the rational human activity that should lead to a positive effect, therefore, AF provokes the growth of bird population. The share of the human interference with nature that results in negative consequences (poaching, nest devastation, change in the natural habitats) leads to a decrease in the bird population. These phenomena are marked with the "predation" variable (PR). There is a feedback between the stocks $(\mathrm{P})$ and $(\mathrm{AF})$, too. Its idea is that with high bird population density the number of 
birds affected by human activity grows. The feedback is realized with the multiplier (MFPI), which increases the flow of the AF increase (FAFI) or leaves it unchanged depending on the density population value. The change of the stocks of the spring high waters by human activity is expressed with the multiplier of dependence of the stock on the anthropogenic factor (MSAF).

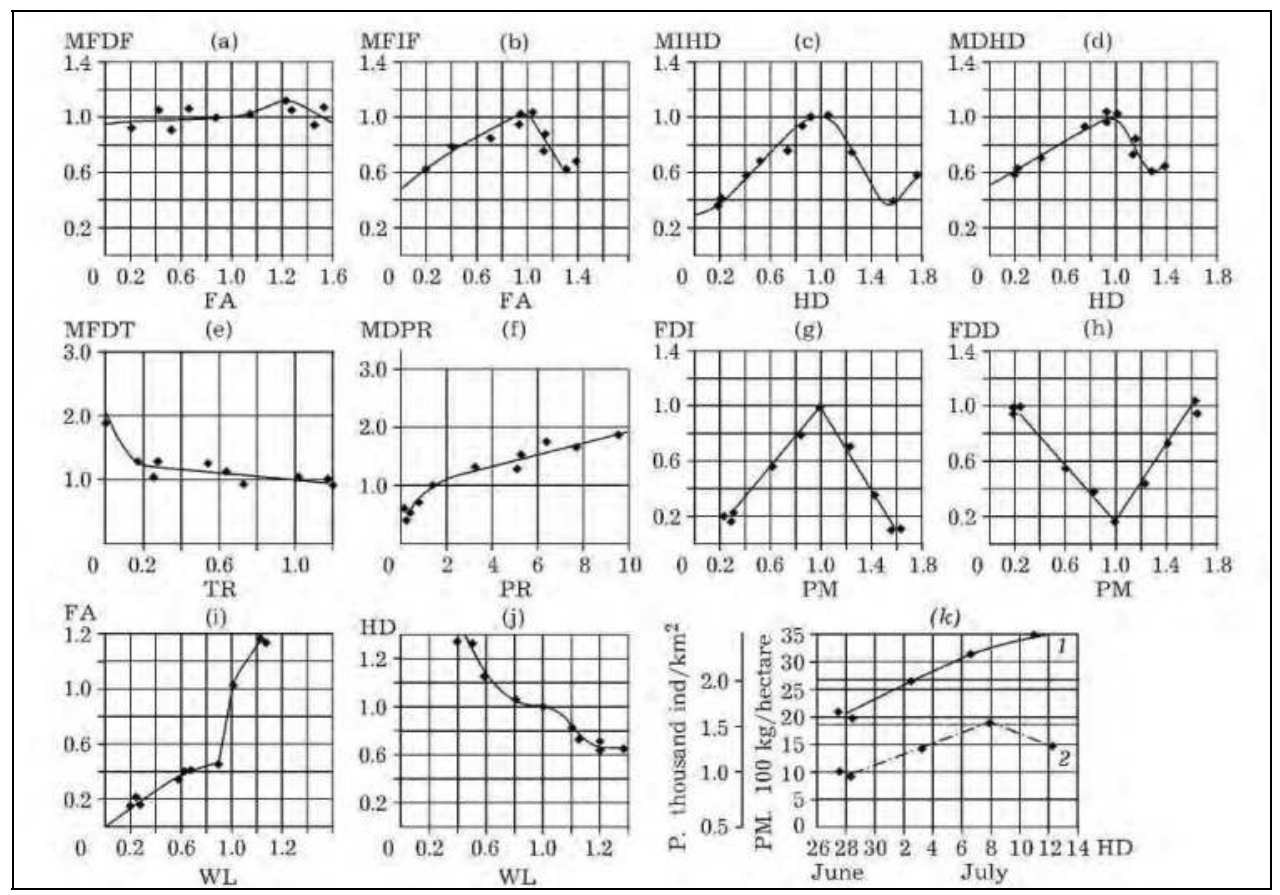

Fig. 4. Empiric graphs of the basic multipliers of the model.

From 1971 to 1989 on the territory of Kolpashevo raion of Tomsk oblast the amelioration was conducted. Our studies show that the amelioration greatly influences the bird population. It allowed us to single it out as the (A) variable. The impact of amelioration on the flow of the bird population decrease is described with the multiplier of the dependence of the flow of the population decrease on amelioration (MFDA).

The spatial-temporal structure and bird population density in the floodplain are determined by the yearly spring high waters. Their levels, time and duration influence the bird distribution over the types of habitats depending on their height situation and on the species composition of the ornitocomplexes. The hydrological regime in the model is set by the following variables: water level (WL), high water duration (HD), and flood-free area (FA). The low high waters cause a decrease in the bird population density due to the free distribution of the meadow and shrub communities over the territory of the floodplain, migration of the water-birds, whereas the high flood increases the bird population density. In the model migration is marked with the (MG) variable, which is a function of WL.

Dependence of migration on the water level is realized through the multiplier of dependence of MG on WL (MMGL). Dependences of FDI and FDD on MG are realized 
through the multipliers MIMG and MDMG respectively. The area of the flood-free territory determines such vital conditions as the presence of territory for nesting, trophic resources and death by predating. With high flood the birds concentrate on the flood-free area (FA), and the waterbirds inflow. The share of the chicks dying of predation increases, and the reproduction success is lowered by the overpopulating. Thus, there are dependencies of FDI and FDD on FA. In the model they are realized through the multiplier of dependence of FDI on FA (MFIF) and multiplier of dependence of FDD on FA (MFDF) (Figure 3 shows only some graphs of dependencies).

The FDI and FDD are influenced by the high water duration (HD), which is a function of the water level (WL). Its value modifies the FDI and FDD through the multipliers of dependence of FDI and FDD on HD (MIHD, MDHD) (see Fig. 3c,d).

A sharp drop in temperature (frosts) in the nesting period leads to the decrease in bird population due to the death of chicks and clutches. To consider the impact of temperature we introduced the variable of temperature regime (TR) into the model, which influenced the FDD through the multiplier of dependence of FDD on temperature (MFDT) (Fig. 3e).

One of the factors limiting the bird population is predation, which is especially dramatic during the nesting period. Under predation we mean an immediate effect on the birds of the preying animals and an indirect human influence that promotes it (depriving the nests their defense devices during hay-making, disclosing the nests and hatches by troubling, etc.). In the model predation is represented with the (PR) variable, which influences the FDD through the multiplier of dependence of FDD on PR (MDPR) (Fig. 3f). Predation depends to a certain degree on the flood-free area (FA), and, as was mentioned above, increases as the areas suitable for nesting decrease. This relation is expressed with the multiplier of dependence of PR on FA (MPRFA).

The model structure includes an auxiliary variable, phytomass of meadows (PM), which expresses the height of meadow vegetation and occupied area (Shepeleva, 1986). If its values are low or high, the bird population decreases. The parameter of phytomass of meadows (PM) influences the FDD through the multiplier of dependence of FDD on phytomass (MDPM), and on FDI, through the multiplier of dependence of FDI on phytomass (MIPM). It is known that the meadow productivity in the floodplain is influences by the duration of the flooding of the floodplain during high water [10]. In the model it is expressed through the multiplier of dependence of the phytomass increase on the high water duration (MPHD) (Fig. 3k).

Migrations conditioned by the character of spring high waters are typical of the birds inhabiting the floodplain. The larger is the number of birds claiming a nesting area, the greater is the influence of the spring high waters.

Duration and high level of the high waters result in an increase in waterbird population accompanied by the general tendency of decrease in the bird population density. Very low high waters decrease a share of water and near-water birds and cause migration of the drymeadow species from the interfluve part into the floodplain. The optimal state of the bird population is observed in the years with high but short high waters. In the model the bird migration is represented as the variable (MG), and dependencies are expressed through the multipliers of FDI and FDD on migration (MIMG and MDMG).

\subsection{Mathematic description of the basic processes}

To describe the analytical structure of the model expressing the quantitative relations between the outside and auxiliary state variables we used the method of finite-difference 
approximation. The outside variables of the model PR, PM, TR, MG, WL are defined as the functions of time $t$. The population density of birds in any moment of time is defined as the density in the antecedent moment of time plus the density added due to FDI and minus the density decreasing due to FDD in the embraced period.

$$
P^{t}=P^{t-1}+\left(T P P^{t-1, t}-T D P^{t-1, t}\right) \cdot \Delta t,
$$

where $P^{t}$ is population density of birds in the given moment of time, ind./ $\mathrm{km}^{2} ; P^{t-1}$, population density of birds in the

antecedent moment of time, ind./ $\mathrm{km}^{2} ; T P P^{t-1, t}$, flow of density increase on the time interval $\Delta t=\{\mathrm{t}-1, \mathrm{t}\}$, ind. $/ \mathrm{km}^{2} ; T D P^{t-1, t}$, flow of density decrease on the interval $\Delta t=$ $\{\mathrm{t}-1, \mathrm{t}\}$, ind. $/ \mathrm{km}^{2} ; \Delta t$, time interval or time step.

The flow of density increase is a component of the loop of positive feedback. The basic flow of increase depends on the density $(\mathrm{P})$ and normal flow of density increase (NFDI). However, the real flow of population density increase depends also on the conditions in the other parts of the system (anthropogenic factor, hydro-logical regime, etc.). The influence of the other parts of the system is introduced by the multipliers, which modify the basic flow of the increase in the density population of birds. Under normal conditions, which are considered a starting point in comparison, the multipliers should not change the basic flow of density increase and are equal to 1 . Then they can acquire the values more or less than 1. The equation of FDI is as follows:

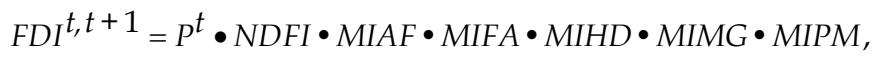

where FFDI ${ }^{t, t+1}$, is the flow of the density increase on the following interval, ind./ $\mathrm{km}^{2}$; $P^{t}$, population density in the given moment, ind./ $\mathrm{km}^{2}$; NFDI, normal flow of the density increase, $1 / \mathrm{t}$; MIAF, the multiplier of dependence of the flow of increase on anthropogenic factors; MIFA, the multiplier of dependence of the flow of increase on the flood-free area; MIHD, the multiplier of dependence of the flow of increase on the high-water duration; MIMG, the multiplier of dependence of the flow of increase on migrations; MIPM, the multiplier of dependence of the flow increase on the phytomass.

The flow of the density decrease is a part of the reversed feedback. The basic flow of decrease equals the population density $P$, multiplied by the normal flow of the density decrease NFDD. The real flow of the decrease depends on the conditions in the other parts of the system. Amelioration, predation, hydrological and temperature regimes, and phytomass of meadows influence the FDD with the multipliers. The equation of FDD is as follows:

$$
F D D^{t, t+1}=P^{t} \bullet N F D D \bullet M F D A \bullet M D H D \bullet M F D T \cdot M D P R \bullet M D P M \bullet M F D A \bullet M D M G,
$$

where $F D D^{t, t+1}$ is the flow of the density decrease on the following interval, ind./ $\mathrm{km}^{2}$; MFDA, the multiplier of dependence of the flow of decrease on the flood-free area; MDHD, the multiplier of dependence of the flow of decrease on the high-water duration; MFDT, the multiplier of dependence of the flow of decrease on temperature; MDPR, the multiplier of dependence of the flow of decrease on predation; MDPM, the multiplier of dependence of the flow of decrease on phytomass; MFD A, the multiplier of dependence of the flow of 
decrease on amelioration; MDMG, the multiplier of dependence of the flow of decrease on migration.

Anthropogenic factor in the model is included in the loop of the positive feedback with the level P. It is supposed that the variable AF is a monotonously increasing function of time. Thus, in the present moment of time it is determined by its value in the previous moment of time plus increase of FAFI (flow of the anthropogenic factor increase):

$$
A F^{t}=A F^{t-1}+F A F I^{t-1, t} \cdot \Delta t,
$$

where $A F^{t}, A F^{t-1}$ are the value of the anthropogenic factors in the present and previous moments of time; FAFI ${ }^{t-1, t}$, the flow of the anthropogenic factor increase on the previous interval $1 / \mathrm{t}$.

The flow of anthropogenic factor increase FAFI equals the basic flow or, in this case, normal flow of anthropogenic factor increase multiplied by the multiplier of dependence of FAFI on population density (MFPI). This multiplier in normal conditions is equal to 1 and begins to work in extreme situation, when the population density of birds drops sharply:

$$
F A F I^{t, t-1}=N F A F I^{t-1} \cdot M F P I^{t},
$$

where $F A F I^{t, t-1}$ is the flow of the anthropogenic factor increase on the following interval $1 / t$; NFAFI, the normal value of the anthropogenic factor $1 / t ; M F P I^{t}$, the value of the multiplier MFPI in the present moment of time.

Let us consider the mathematical description of the auxiliary variables: variable WL is the function of time and is given a priori: $\mathrm{WL}=\mathrm{F}(\mathrm{t})$, variable TR is also a predictable function of time TR $=\Phi(t)$.

In the model the variable PR is determined by its value in normal conditions and state of two multipliers in the given moment of time, i.e.

$$
P R^{t}=N P R \cdot M P R F A^{t} \cdot M P R A F^{t},
$$

where $P R^{t}$ and NPR are the parameters of predation in the present moment of time and corresponding to the normal

conditions; MPRFA ${ }^{t}, M P R A F^{t}$, the multipliers of dependence of predation on the floodfree area and anthropogenic factor.

The duration of the high-water and the flood-free area depend only on the water level:

$$
H D=\Psi(W L), F A=\Omega(W L), M G=\Lambda(W L),
$$

The variable $A$ in the model is represented by the relative value Sa/S, where Sa is the area of the ameliorated lands, S, the area of Kolpashevskii raion.

The parameter of phytomass in the present moment of time is determined by its normal value multiplied by the multiplier of dependence of the meadow phytomass on the highwater duration (MPHD):

$$
P M^{t}=N P M \cdot M P H D^{t},
$$

where $P M^{t}$ is phytomass in the given moment of time $t$, centner/hectare; NPM, normal phytomass, centner/hectare; 
$M P H D^{t}$, the multiplier of dependence of the phytomass on the high-water duration in the given moment of time.

The equation of the initial conditions is written in the following form: $t_{0}$ is the initial reference point; $\mathrm{P}_{0}$, initial density of bird population, ind./ $\mathrm{km}^{2}$.

The values of FDI, FDD and FAFI necessary for the first calculation of the model are as follows:

$$
\begin{gathered}
F D I^{t o, t o+1}=\operatorname{Po}^{t} \cdot N F D I \bullet M I F A \bullet M I H D \bullet M I A F \bullet M I P M, \\
F D D^{t o, t o+1}=P o \bullet N F D D \bullet M F D A \bullet M D H D \bullet M F D T \cdot M D P R \bullet M D P M \bullet M F D A, \\
F A F I^{t o, t o+1}=N F A F I \bullet M F P I^{t} .
\end{gathered}
$$

In the system the following types of equations are used: the equation of stocks, of flows, auxiliary (describing the auxiliary variables), and of initial conditions.

When considering an interval of time, first, the equations of stocks are solved (it is believed that the equations of the initial conditions are solved before). Then obtained results are used in the equation of the flows. The auxiliary equations are introduced for ease and are solved immediately after solving the equations of stocks.

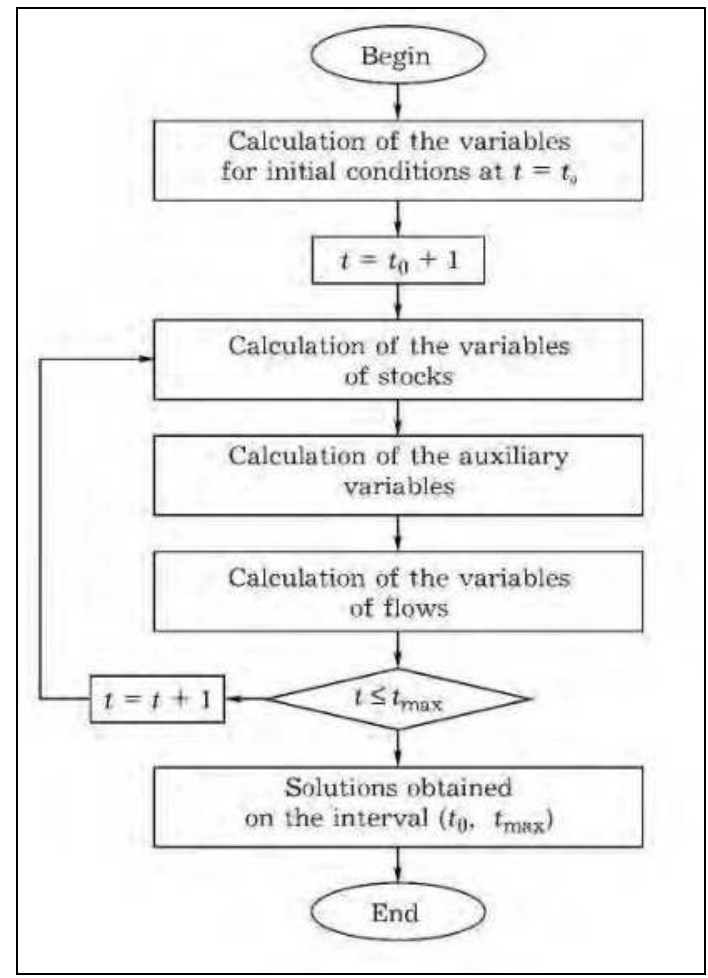

Fig. 5. Logical scheme of calculation of the system of equations. 


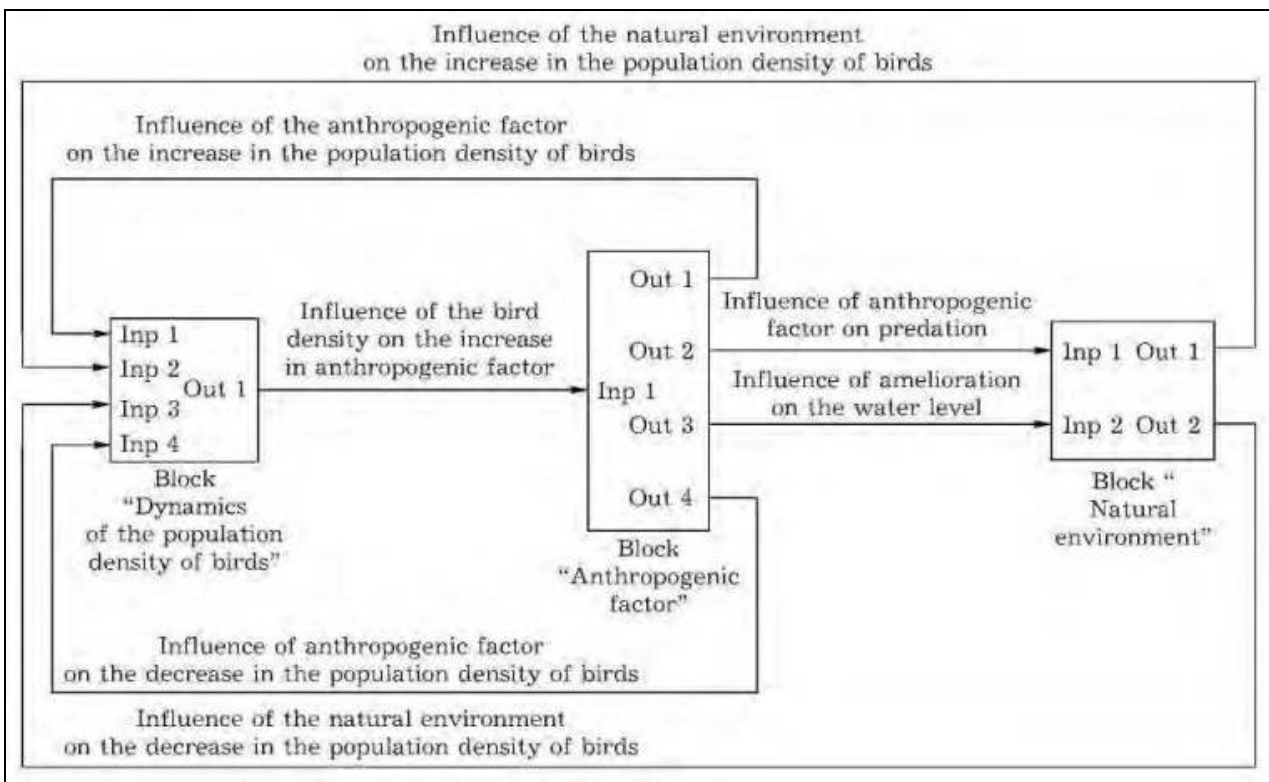

Fig. 6. Basic model of the dynamics of the bird population in the floodplain of the $\mathrm{Ob}$ realized with the help of MATLAB 5.2.1.

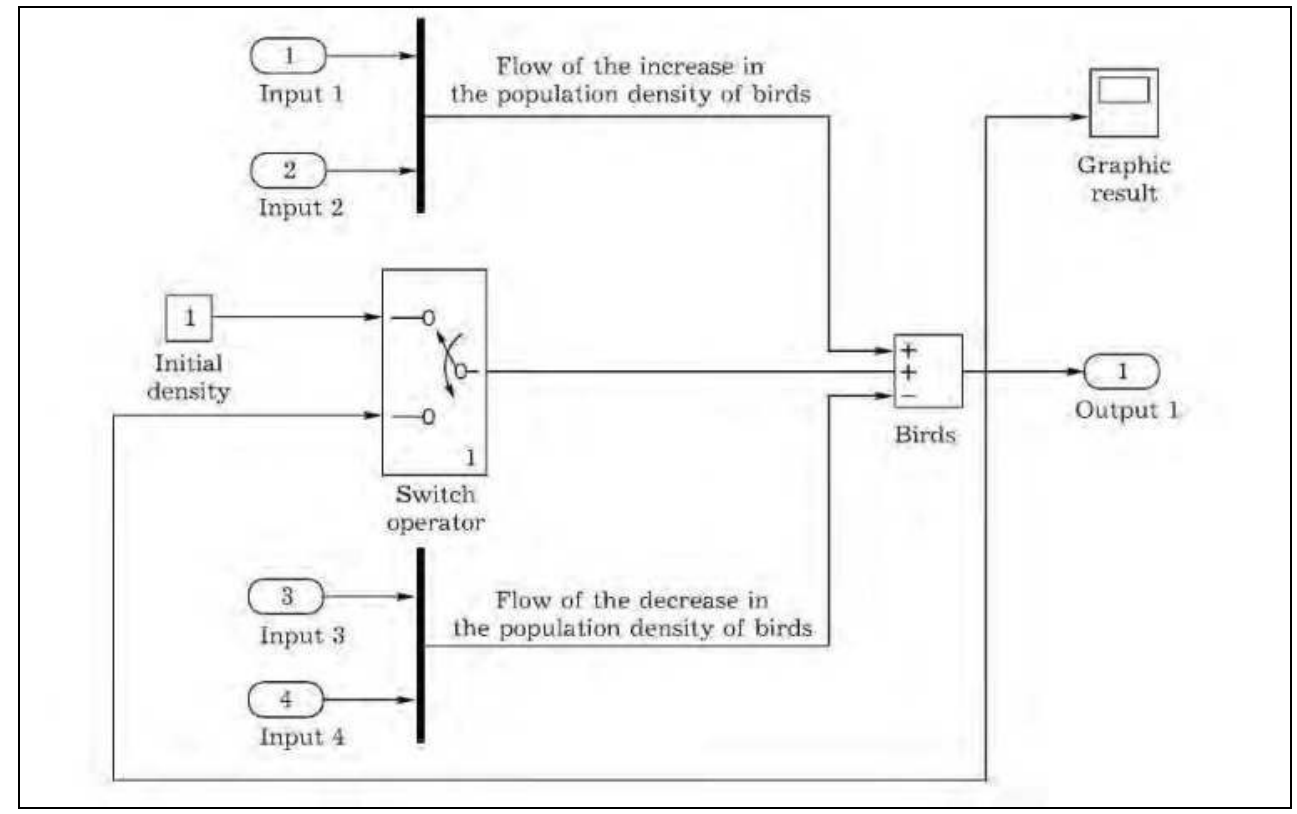

Fig. 7. Block "Dynamics of the bird population". 
The general scheme of the equations is as follows:

$$
P^{t o}=P o
$$

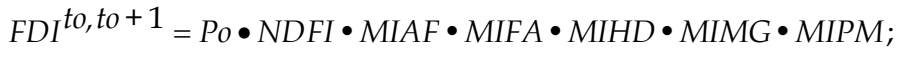

$$
F D D^{t o, t o+1}=P o \bullet N F D D \bullet M F D A \bullet M D H D \bullet M F D T \cdot M D P R \bullet M D P M \bullet M F D A ；
$$

$$
\text { FAFI }^{\text {to, to }+1}=N F A F I \cdot M F P I^{t}
$$

$$
A F^{t o}=A F o
$$

$$
P^{t}=P^{t-1}+\left(F D I^{t-1, t}-F D D^{t-1, t}\right) \cdot \Delta t
$$

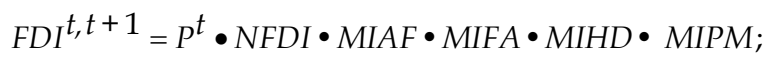

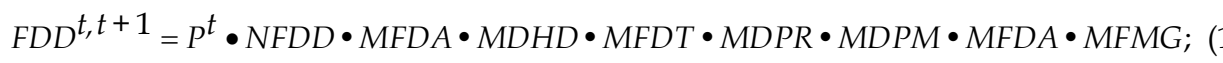

$$
\begin{gathered}
A F^{t}=A F^{t-1}+F A F I^{t-1, t} \cdot \Delta t, \\
F A F I^{t, t+1}=N F A F I \cdot M F P I^{t} . \\
W L=F(t) ;
\end{gathered}
$$

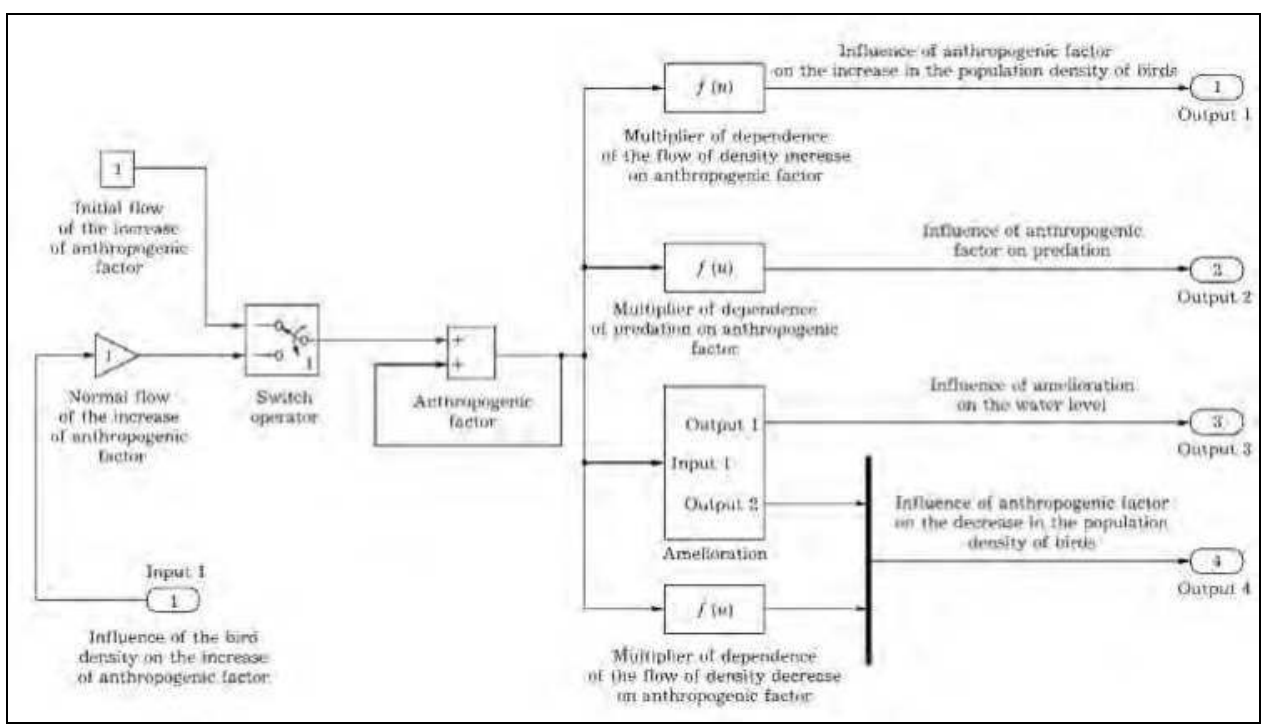

Fig. 8. Block "Anthropogenic factor". 


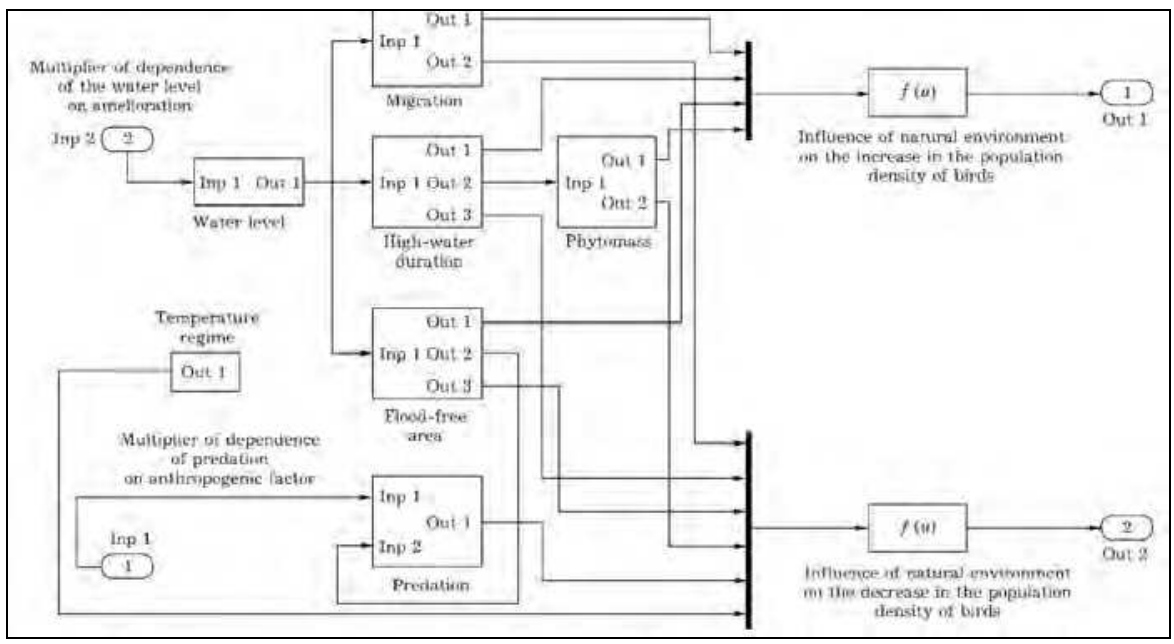

Fig. 9. Block "Natural envaronment".

$$
\begin{gathered}
H D=\Psi(W L) ; \\
F A=\Omega(W L) ; \\
T R=\Phi(t) ; \\
M G=\Lambda(W L) ; \\
P R^{t}=N P R \bullet M P R A^{t} \bullet M P R A F^{t} ; \\
A=\mathrm{f}(t) ; \\
P M^{t}=N P M \bullet M P H D^{t} .
\end{gathered}
$$

the scheme (Fig. 4). The value of any multiplier is chosen automatically from the composed tables of multipliers for each year. The model is also realized with the help of MATLAB 5.2.1 software (D'yakonov et al., 2001, Gul'tyaev, 1999). This software was chosen because in includes the system of visual modeling SIMULINK. SIMULINK allows one to combine two basic approaches to the model creation, analytical and imitational, to consider nonlinear problems with continuous and discrete time. There is a library of blocks in SIMULINK, which are the means for developing and building the models (S-models). It is possible to create new elements and group them into blocks and to create hierarchic models. The S-models with hierarchic structure of unlimited nesting are possible to create. The results can be presented in both graphic and digital forms. The process of creating the S-models with SIMULINK consists in the constructing a scheme from the blocks preserved in the library SIMULINK. To make an S-model the Drag-and-Drop technology is used, which facilitates the work.

The Figs. 2-5 show an S-model with hierarchic structure and three basic blocks with a link between them: "Dynamics of the population density of birds", "Anthropogenic factor", and "Natural environment", each of them is a model of a lower level. 
The quantitative presentation of the stock, flow and auxiliary variables is based on the experimental data on the real system. When determining the constants and variables, the conditions of 1977 were taken as the reference points, i.e., the state of the system is described as related to this year. The dynamics of the population density of birds is followed for 19772000, with spring-summer period considered within each year conditions. The step of modeling is accepted as equal to one year. All variables of the model are characterized with relative values.

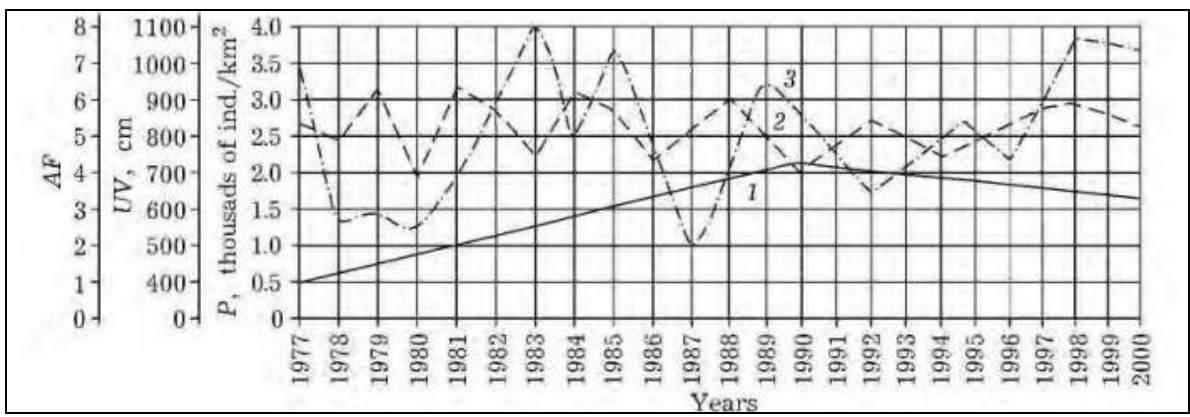

Fig. 10. Ratio of basic values characterizing the state of an ornithocomplex, as anthropogenic factor changes: $1, \mathrm{AF} ; 2, \mathrm{WL} ; 3, \mathrm{P}$.

\subsection{The results of the modeling}

The results obtained upon modeling represented on Fig. 6 confirmed the supposition that hydrological regime is the basic factor regulating the bird population. Analysis of the obtained data shows that the highest density of birds in the flood-plain of the middle $\mathrm{Ob}$ is determined by the high-waters ( $50 \%$ of provision), the lowest values of the density is determined by low high-waters (less than $75 \%$ of provision), while high high-waters give more than $25 \%$ of provision. The development of amelioration reduced the times of the flood-plain flooding, the canal cutting resulted in the increase in the number of swimming and near-water groups of birds in the first half of summer, and fast drying up of the floodplain attracted birds of forbs meadows. However, the factor of disturbance, nest destruction, due to machinery working, resulted in a decrease in the population density of birds in 19902000 and change in the structure of the bird community on the whole.

\section{Conclusion}

The partial change in hydrological regime and industrial use of the flood-plain lands with moderate amelioration does not affect the dynamics of birds. If the area of amelioration grows to $50 \%$ of the total area of the flood-plain, the existing ecosystem will be destroyed in the lowest high-waters (75\% of provision and less) and will not be able to restore for 4 years. It is necessary to control the scale of amelioration and not to allow the system to begin irrevocable destruction.

The built model is of theoretical and applied character. The structure of the model can be used as basic for biotic components of the flood-plain ecosystem when predicting the basic tendencies of their behavior and monitoring. It is built for the component which plays an indication role. Introduction of certain changes into the parameters of water regime can help in determining the upper and lower limits. When they are passed, the flood-plain ecosystem begins to change in general. 
For conservation of ecosystem values in the $\mathrm{Ob}$ river floodplain the following aspects should considered:

- Preferably land use types with low impact should be developed: (eco)-tourism, recreation, trade, small scale agriculture (diary, pastures)

- Preservation an equally balanced land use between natural and semi-natural ecosystems, given the ecological potentials

- Hay-making is most suitable land use for wet meadows

- $\quad$ Land reclamation development should focus on high floodplain parts

- Development of health-improving recreation.

The conservation of natural resources is achieved by combination of two units. The first unit provides annual observation of high water regime of Middle $\mathrm{Ob}$ flood-land in comparison with long-term data. Second unit is human activity management, which includes the preparation of recommendations for the main resource users: administrators, farmers, hunters and fisherman. It is expected that by the management measures to be developed within this scheme the effective land use may increase with up to $60 \%$. The concept hydroecological monitoring of the Middle Ob River floodplain has been developed on a platform for the organization of scientifically based, regionally adapted, and ecologically regulated nature management.

Author to express one's thanks of professor Tomsky State University, PhD A.M. Adam for data presentation and cause in hard expedites.

\section{References}

Adam A. M. \& Bolotnov, V. P., (1982). Analysis of Influence of the Spring High Water over the Structure of the Bird Population in the Floodplain of the Middle Ob for the Purpose of Nature Protection. Deposited in VINITI No. 1040-82 [in Russian].

Adam A. M., Bolotnov V. P., and Sekisova S. E., (2001), inProblems of Geography of Siberia .TGU, Tomsk, , Issue 24, pp. 211-218 [in Russian].

Adam A. M. and Mamin R. G., Natural Resources and Ecological Safety of West Siberia (POLTEKS, Moscow, 2000) [in Russian].

Adam A. M., Novoselov A. L., and Chenurnykh N. V. (2000), Ecological Problems of the Regions of Russia (VINITI, Moscow, ) [in Russian

Bolotnov V. P. , Sekisova,S. E., and Adam A. M., (2001). "Environment of Siberia, the Far East, and the Arctic," in Selected Paper Presented at the International Conference ESFA 2001, Tomsk, Russia (International Research Center of Environmental Physics and Ecology, Russian Academy of Science, 2001), pp. 348-361.

Gul'tyaev A. K., (1999) MATLAB 5.2.1. Imitation Modeling inWindows: Practical Manual (KORONA print, Sankt-Petersburg) [in Russian].

D'yakonov V. P. ,Abramenkova I. V., and Kruglov V. V., (2001). MATLAB 5.2.1 with Bump Packs (Knowledge, Moscow) [in Russian].

Forrester J., (1978).World Dynamics (Nauka, Moscow) [Russian translation].

Ravkin, Yu. S., (1984). Spatial Organization of the Bird Population in the Forest Zone (West and Central Siberia) (Nauka, Siberian Branch, Novosibirsk,) [in Russian].

Shepeleva L. F. (1986), Ekologiya, No. 2, 3.

Vartapetov D. G., (1984). Birds of the Taiga Interfluves of the West Siberia (Nauka, Siberian Branch, Novosibirsk, ) [in Russian].

Yudkin V. A., Ravkin Yu. S., Blinov V. N., et al., (1987). Spatial-Temporal Dynamics of the Fauna (Birds and Small Mammals) (Nauka, Siberian Branch, Novosibirsk,) [in Russian]. 


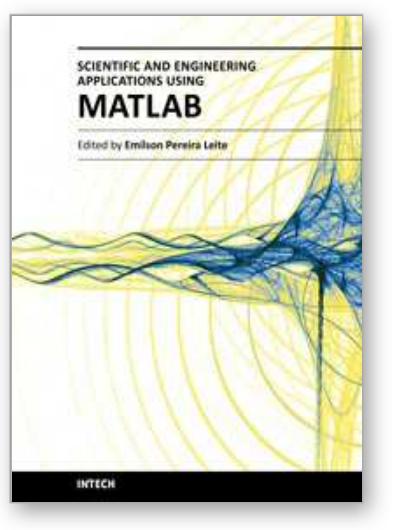

\author{
Scientific and Engineering Applications Using MATLAB \\ Edited by Prof. Emilson Pereira Leite
}

ISBN 978-953-307-659-1

Hard cover, 204 pages

Publisher InTech

Published online 01, August, 2011

Published in print edition August, 2011

The purpose of this book is to present 10 scientific and engineering works whose numerical and graphical analysis were all constructed using the power of MATLABÂ® tools. The first five chapters of this book show applications in seismology, meteorology and natural environment. Chapters 6 and 7 focus on modeling and simulation of Water Distribution Networks. Simulation was also applied to study wide area protection for interconnected power grids (Chapter 8) and performance of conical antennas (Chapter 9). The last chapter deals with depth positioning of underwater robot vehicles. Therefore, this book is a collection of interesting examples of where this computational package can be applied.

\title{
How to reference
}

In order to correctly reference this scholarly work, feel free to copy and paste the following:

Vladimir Petrovich Bolotnov (2011). The Analysis of Influence of River Floods on Biotic Components of Floodplain Ecosystems with the Help of MATLAB Simulation, Scientific and Engineering Applications Using MATLAB, Prof. Emilson Pereira Leite (Ed.), ISBN: 978-953-307-659-1, InTech, Available from:

http://www.intechopen.com/books/scientific-and-engineering-applications-using-matlab/the-analysis-ofinfluence-of-river-floods-on-biotic-components-of-floodplain-ecosystems-with-the-hel

\section{INTECH}

open science | open minds

\section{InTech Europe}

University Campus STeP Ri

Slavka Krautzeka 83/A

51000 Rijeka, Croatia

Phone: +385 (51) 770447

Fax: +385 (51) 686166

www.intechopen.com

\section{InTech China}

Unit 405, Office Block, Hotel Equatorial Shanghai

No.65, Yan An Road (West), Shanghai, 200040, China 中国上海市延安西路65号上海国际贵都大饭店办公楼 405 单元

Phone: +86-21-62489820

Fax: +86-21-62489821 
(C) 2011 The Author(s). Licensee IntechOpen. This chapter is distributed under the terms of the Creative Commons Attribution-NonCommercialShareAlike-3.0 License, which permits use, distribution and reproduction for non-commercial purposes, provided the original is properly cited and derivative works building on this content are distributed under the same license. 